\title{
SPECIAL STRUCTURES OF GRAPHITE STEELS AFTER HIGH-ENERGY ELECTRON IRRADIATION
}

\author{
N.M. Alexandrova \\ Central Research Institute of Iron and Steel Industry (State Scientific Centre) \\ Moscow 107005, Russia.
}

The effect of high-energy electron irradiation on the structure and properties of the graphite steels was investigated. It was shown that singleand multicycle irradiation allows the improvement of hardness and ductility $(\approx$ twice). A partial dissolution of the graphite, carbides redistribution, and refinement of the grain size allow the formation of the favorable surface structure after irradiation.

PACS numbers: $61.80 . \mathrm{Fe}, 61.82 . \mathrm{Bg}$

\section{Introduction}

Graphite steels have been used for the machine details under the tight wear conditions, including the rolling equipment. It is important that the shape and distribution of the graphite phase have been strongly dependent on the melting technology (raw materials purity, deoxidizing, inhibitors used, etc.). As a result, the stability of consumptional properties of these steels was found to be quite insufficient for the modern technique $[1,2]$.

It is known that the high-energy electron irradiation leads to the fast surface heating to the high temperature (depth $\approx 1-2 \mathrm{~mm}$ ) with the simultaneous formation of the radiation defects, and to subsequent fast cooling due to the heat flow into the bulk. As a result, a special material structure can be realized. The formation of the special surface structure is very important for the improvement of the material's consumptional properties.

The optimization of the surface structure and technological properties of the graphite steels by means of the high-energy electron irradiation have been the aim of the present work.

\section{Experimental}

Electron irradiation was done using different types of the electron accelerators $(E=1.5 \mathrm{MeV}$ and $5.0 \mathrm{MeV}$, irradiating conditions: $I=120 \mathrm{~mA}, i=$ $\left.55 \mathrm{~mA} / \mathrm{mm}^{2}, v=5 \mathrm{~mm} / \mathrm{s}\right)$. As-cast steels were treated without smelting the material surface. Irradiation was undertaken in accordance with two treatment regimes: (1) single-step scanning of the surface and (2) multicycle irradiation. 
The following grades of graphite steels were studied: economically-alloyed graphite steel $(1.29 \% \mathrm{C}, 1.6 \% \mathrm{Si}, 0.5 \% \mathrm{Mn}, 0.06 \% \mathrm{Cr}, 0.06 \% \mathrm{Ni}, 0.01 \% \mathrm{~S}, 0.01 \% \mathrm{P})$ and high-alloyed graphite steel $(1.22 \% \mathrm{C}, 1.6 \% \mathrm{Si}, 0.4 \% \mathrm{Mn}, 0.59 \% \mathrm{Cr}, 0.87 \% \mathrm{Ni}, 0.2 \% \mathrm{Mo}$, $0.01 \% \mathrm{P})$.

Such experimental methods as X-ray analysis, microanalysis, optical microscopy, and different mechanical tests were used for the study.

\section{Experimental results and discussion}

It has been found that the irradiation causes the surface hardening of the steels (up to $\approx 3 \mathrm{~mm}$ in depth). Irradiation intensity was found to be responsible for the hardening level, while the depth is controlled by the electron energy.

Single-step irradiation causes an essential increase in the hardness in the depth range up to $1 \mathrm{~mm}$. The following structure components were observed during the analysis of the surface layer: martensite, graphite inclusions, and carbides.

Multicycle irradiation allows an additional increase in the hardness $(\approx 1.5$ times). This kind of treatment causes a local modification of the structure and morphology of the graphite inclusions as well as the retained austenite fraction. It takes place, first of all, due to the $\alpha \leftrightarrow \gamma$ transformation, partial or complete dissolution of carbides and graphite inclusions with accompanying the formation of the retained austenite. The structure after multicycle treatment is substantially different from that after the single treatment; in addition to the previously mentioned structure components, the ledeburite plates are formed, while the matrix contains disperse martensite needles.

Disperse martensite is formed during the multicycle irradiation. Let us mention that the ledeburite has not been observed in non-irradiated steels.

Figure 1a presents the distribution of microhardness in the economically-alloyed steel. The irradiated layer $(t \approx 0.9 \mathrm{~mm})$ can be subdivided into two zones:

- irradiated zone $\left(H K=480 \mathrm{~N} / \mathrm{mm}^{2}\right)$,

- transitional zone $\left(H K \approx 300 \mathrm{~N} / \mathrm{mm}^{2}\right), t \approx(0.6-0.9) \mathrm{mm}$.

Maximum microhardness is observed at $0.4 \mathrm{~mm}$ of depth due to the peak of the energy transfer.
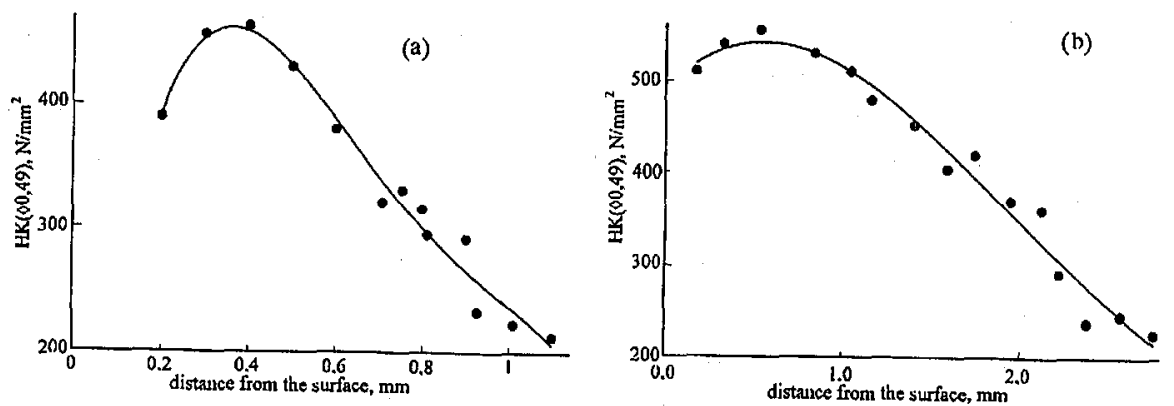

Fig. 1. Microhardness distribution along the normal direction to the irradiated surface: (a) economically-alloyed graphite steel, (b) high-alloyed graphite steel. 
The hardness distribution for the high-alloyed steel (Fig. 1b) was found to be analogous with the above described. The thickness of the hardened layer was found to increase with the increase in the electron energy $(E=5 \mathrm{MeV})$.

The volume fraction of austenite after irradiation was found to be $\approx 35 \%$ in the high-alloyed steel (which is higher than in the economically-alloyed steel). In this case, the lattice parameter of the $\alpha$-phase has been decreased from $a_{k}^{\alpha}=$ $2.8637 \AA$ to $a_{k}^{\alpha}=2.8621 \AA$, which may be caused by the carbides redistribution.

$\mathrm{X}$-ray investigation of the high-alloyed steel shows that irradiation causes a partial carbides dissolution and the matrix enrichment in C. It supports the stabilization of the retained austenite, and the $\alpha+\gamma$ structure has been formed during the fast cooling. The volume fraction of martensite $(\alpha)$ was found to be about $65 \%$, and the retained austenite $(\gamma)-35 \%$.

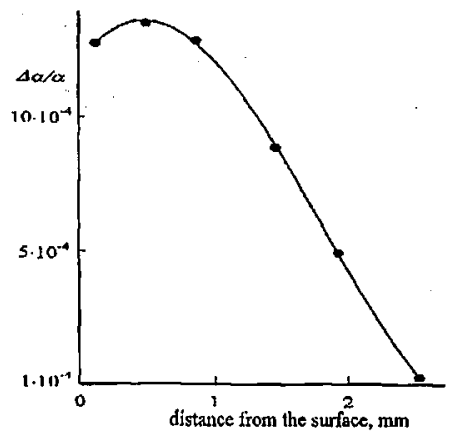

Fig. 2. Distribution of microstress along the normal direction to the irradiated surface for the economically-alloyed graphite steel.

X-ray investigation of the residual microstresses was carried out with the help of diffractometer DRON-3 (Co $K_{\alpha}$ radiation), and the ratio $\Delta \alpha / \alpha$ was determined using reflexes (220), (110). The X-ray analysis shows that irradiation causes an increase in the residual stresses. Figure 2 presents $\Delta \alpha / \alpha$ distribution along the normal direction to the surface. The maximum values of $\Delta \alpha / \alpha$ were observed at the depth of $\approx 0.5 \mathrm{~mm}$.

Let us mention that the structure dispersing allows the improvement of the impact strength $(\approx$ twice $)$. It can be noted also that the graphite inclusions allow a good lubrication, but the viscous austenite-based component allows a good shock-resistance. As a result, the described treatment increases remarkably the wear resistance, which is very important for the practice. It is also important that the increase in the thermal durability can be realized using the partial surface treatment (alternating of the irradiated and non-irradiated zones).

\section{Conclusion}

High-energy electron irradiation of graphite steels causes the surface hardening $(0.8-2.2 \mathrm{~mm})$, accompanied by the increase in ductility (1.5-2 times) and hardness $(\approx$ twice $)$. 
The increase in hardness is caused by the formation of martensite, disperse carbides and by the increase in the internal stresses, in the same time the increase in ductility is caused by the grain-size refinement and the appearance of the $\gamma$-phase.

The formation of the ledeburite and strain-hardened austenite upon irradiation leads to the development of technology for the improvement of the wear resistance. In this case, wear resistance can be controlled by the fraction of ledeburite (formed due to the graphite dissolution), stress-hardened austenite, and non-dissolved portion of graphite.

High-energy electron irradiation is very effective for the modification of properties in the graphite steels. The obtained multilayer structures allow a high workability of the friction pair with the graphite steel component.

\section{References}

[1] K.P. Bunin, A.A. Baranov, E.N. Pogrebnoy, Graphitization of Steel, Ukrain. Acad. Sci. Publ., Kyiv 1961, p. 86 (in Russian).

[2] T.S. Skoblo, S.I. Rudyuk, Ferrous Metallurgy 16, 2 (1988) (in Russian). 